\title{
High density lipoprotein cholesterol concentration as a predictor of coronary heart disease in West Indian men
}

\author{
G J Miller, G L A Beckles, G H Maude, D C Carson, S G L Price
}

MRC Epidemiology and Medical Care Unit, Northwick Park Hospital, Watford Road, Harrow, Middlesex HA1 3UJ, United Kingdom G J Miller

Caribbean

Epidemiology Centre

(PAHO/WHO),

Trinidad

G L A Beckles

Department of

Epidemiology and

Population Studies,

London School of

Hygiene and Tropical

Medicine, Keppel St,

London WC1

G H Maude

D C Carson

Department of

Clinical Pathology, St

Thomas's Hospital

Medical School,

London SE1

S G L Price

Correspondence to:

Dr Miller

Accepted for publication September 1989

\begin{abstract}
Study objective-The aim of the study was to determine whether the inverse association between high density lipoprotein cholesterol concentration and risk of coronary heart disease described in people of European stock was also present in other racial groups.
\end{abstract}

Design-The study was a prospective population survey. Cardiovascular risk factors were examined, including fasting serum lipid estimation (obtained at recruitment).

Setting-This was a community based study within a defined survey area in Trinidad.

Participants-All men aged between 35 and 69 years within the survey area were identified and followed between 1977 and 1986. Analysis was confined to those of African, Asian Indian, and mixed descent who were free of coronary heart disease at entry $(n=960,69 \%$ of age eligible men in the survey population).

Measurements and main results -64 men developed coronary heart disease during the study period. A strong inverse curvilinear relation was found between high density lipoprotein cholesterol and coronary heart disease incidence $(p<0.005)$, independent of age or other relevant characteristics including low density lipoprotein cholesterol.

Conclusions-A low serum concentration of high density lipoprotein cholesterol is a risk factor for coronary heart disease in non-whites as well as in whites.

A strong and inverse relation between plasma high density lipoprotein cholesterol concentration and risk of coronary heart disease exists in many countries of European stock. ${ }^{1-3}$ The evidence that high density lipoprotein protects against atheroma ${ }^{4}$ suggests that its association with coronary heart disease will apply similarly to other racial groups. To test this possibility, a prospective survey was undertaken in Trinidad, West Indies.

\section{Methods}

The population and recruitment methods have been described. ${ }^{5}$ Briefly, all men aged 35-69 years within the defined survey area in Trinidad were identified by household census and followed between 1977 and 1986. Previous medical history (including angina pectoris ${ }^{6}$ ) and smoking habit were recorded. Ethnic origin was assessed from the family history. Those judged to be at least $75 \%$ African, Asian Indian, European, Chinese, Lebanese or Syrian by descent were grouped accordingly, and others were designated "Mixed". Fasting blood samples were taken at the time of recruitment. Separate aliquots of fasting serum were used to prepare high density lipoprotein by a heparin-manganese method, ${ }^{7}$ and very low density lipoprotein free serum by a sodium lauryl sulphate procedure. ${ }^{8}$ All preparations and a sample of whole serum were subsequently analysed for cholesterol and triglyceride by enzymatic procedures. ${ }^{5}$ Low density lipoprotein cholesterol concentration was derived by difference. Fasting blood glucose was measured by the Nelson-Somogyi method.

Blood pressure was recorded on two occasions on the left arm with a random zero sphygmomanometer and the average used in the analysis. A resting electrocardiogram (ECG) was recorded with a Cambridge VS $4 S$ instrument, read against a reticle scale (Edmund Scientific, Washington, New Jersey), and coded to Minnesota criteria. ${ }^{9}$ Biceps, triceps, subscapular and suprailiac skinfolds were measured in duplicate and summed for statistical analysis.

\section{FOL LOW UP}

All men were visited annually and those with a history suggestive of recent cardiovascular disease were examined clinically. Survivors were offered an ECG at 5 years. Deaths were traced through family informants, death registers and hospital records. The underlying cause of morbidity or mortality was reached after independent review of all documentation by two physicians without reference to baseline status, with a third as arbiter when necessary. Events in which coronary heart disease was considered to be the underlying cause (coronary events) were grouped by mode of presentation according to ICD $\operatorname{codes}^{10} 410-4$ (ischaemic heart disease), 427 (dysrhythmias), 428 (heart failure), 429.1 (myocardial degeneration), 798.1-2 (sudden death), or a new major $Q$ wave (code $1_{1}$ ) in $V_{5}$ of the 5 year ECG (silent myocardial infarction).

\section{STATISTICAL ANALYSIS}

The analysis was confined to men of African, Asian Indian, and Mixed descent, since its purpose was to search for an association between high density lipoprotein cholesterol and coronary heart disease in non-Europeans. Small numbers of Chinese, Lebanese and Syrians were also excluded. Men with coronary heart disease at baseline (a positive history of angina pectoris or acute myocardial infarction, or a major $Q$ wave 
(code $1_{1}$ ) in lead $V_{5}$ of the entry ECG), those without a baseline ECG, and those who developed a coronary event within one month of recruitment were also excluded from the analysis. Survival time was taken from baseline venepuncture to the first coronary event or until death, default or completion of follow up on 31st December 1986.

Analysis of survival time to a first coronary event was performed with Cox's proportional hazards model. 11 The effect of age at entry on coronary heart disease hazard was allowed for by stratification into 5 year age groups. Ethnic effects were sought firstly by classification of men as either Indian or non-Indian, and secondly with dummy variables to distinguish the three ethnic groups. The association between high density lipoprotein cholesterol and coronary heart disease was not influenced by the procedure chosen. The regression coefficients from the analysis were used to derive standardised hazard ratios, where the ratio $=$ exponential (coefficient $\times$ standard deviation). This ratio expressed the change in coronary heart disease hazard associated with an increase of one standard deviation in the predictor variable.

\section{Results}

Of 1386 age eligible men resident in the survey area at recruitment, $1246\left(90^{\circ}{ }_{0}\right)$ were examined. One hundred and four $\left(8^{\circ}{ }_{0}\right)$ of the respondents had evidence of coronary heart disease at baseline, and $159\left(14^{\circ}{ }_{0}\right)$ of the remainder were excluded by reason of ethnic origin. Serum high density lipoprotein cholesterol concentration was missing in another 23 men, leaving 960 or $69^{\circ}$ of the original 1386 men available for statistical analysis.

Table I presents these 960 men by age and ethnic group, together with the numbers who had a coronary event. Of the 64 coronary events documented, $38\left(59^{\circ}{ }_{0}\right)$ were in Indians, $23\left(36^{\circ}{ }_{0}\right)$ were in Africans, and only three $\left(5^{\circ}{ }_{0}\right)$ were in men of mixed descent, who accounted for $22^{\circ}{ }_{0}$ of those included in the analysis. Thirty four events $\left(53^{\circ}{ }_{0}\right)$ were classified as acute myocardial infarction, 12 $(19 \%)$ as angina pectoris, one as a fatal dysrhythmia, seven $\left(11^{\circ}{ }_{0}\right)$ as cardiac failure, two as myocardial degeneration, four $\left(6^{\circ}{ }_{0}\right)$ as sudden death, and four as silent myocardial infarction.

The mean (SD) high density lipoprotein cholesterol concentration was $0.98(0.43) \mathrm{mmol} /$ litre. After allowance for age at entry, the log transformed value of high density lipoprotein cholesterol was more strongly associated with coronary heart disease hazard (log likelihood $\left.\chi^{2}=7.99 ; p<0.005\right)$ than the untransformed value $\left(\chi^{2}=4.20 ; p=0.04\right)$. Thus $\log _{10}$ high density lipoprotein cholesterol was used in further

Table I Numbers of participants by age and ethnic group, with number of coronary events

\begin{tabular}{|c|c|c|c|c|c|c|c|c|}
\hline \multirow{2}{*}{$\begin{array}{l}\text { Age group } \\
\text { (years) }\end{array}$} & \multicolumn{2}{|c|}{ African } & \multicolumn{2}{|c|}{ Indian } & \multicolumn{2}{|c|}{ Mixed } & \multicolumn{2}{|c|}{ Totals } \\
\hline & $\bar{n}$ & Events & n & Events & $\mathbf{n}$ & Events & $\overline{\mathrm{n}}$ & Events \\
\hline $\begin{array}{l}35-44 \\
45-54 \\
55-64 \\
65-74\end{array}$ & $\begin{array}{r}94 \\
113 \\
137 \\
80\end{array}$ & $\begin{array}{r}2 \\
5 \\
11 \\
5\end{array}$ & $\begin{array}{r}109 \\
105 \\
86 \\
21\end{array}$ & $\begin{array}{r}7 \\
16 \\
11 \\
4\end{array}$ & $\begin{array}{l}75 \\
64 \\
57 \\
19\end{array}$ & $\begin{array}{l}2 \\
1 \\
0 \\
0\end{array}$ & $\begin{array}{l}278 \\
282 \\
280 \\
120\end{array}$ & $\begin{array}{r}11 \\
22 \\
22 \\
9\end{array}$ \\
\hline $35-74$ & 424 & 23 & 321 & 38 & 215 & 3 & 960 & 64 \\
\hline
\end{tabular}

\section{Discussion}

This study has shown that the association between a low high density lipoprotein cholesterol and high coronary heart disease risk is not confined to populations of European descent but applies also to non-white communities. As elsewhere, ${ }^{1-3}$ the relation is independent of other coronary heart disease risk factors including low density lipoprotein cholesterol and serum triglyceride concentrations, blood glucose concentration and blood pressure. The 
Table II Standardised hazard ratio (SHR) for $\log _{10}$ high density lipoprotein (HDL) cholesterol after allowance for additonal risk factors

\begin{tabular}{lcc}
\hline Additional risk factor & $\begin{array}{c}\text { SHR for log } \\
\text { HDL cholesterol }\end{array}$ & $\mathrm{p}$ \\
\hline Age alone & 0.70 & 0.003 \\
Age + LDL cholesterol & 0.73 & 0.01 \\
Age + serum triglyceride & 0.70 & 0.008 \\
Age + blood glucose & 0.72 & 0.01 \\
Age + sum of 4 skinfolds & 0.68 & 0.003 \\
Age + systolic pressure & 0.67 & 0.002 \\
Age + diastolic pressure & 0.69 & 0.003 \\
Age + ethnic group & 0.77 & 0.004 \\
All of the above & 0.73 & 0.025 \\
\hline
\end{tabular}

consistency of the findings across several ethnic groups is further evidence for a fundamental role of high density lipoprotein cholesterol in the disease process, with high concentrations affording protection.

Only one other study has sought an association between high density lipoprotein cholesterol and coronary heart disease in a non-white population. Equivocal results were given by an analysis of data for $\mathbf{4 6 5}$ black men randomised to "usual care" in the American Multiple Risk Factor Intervention Trial. ${ }^{12}$ This study was not designed to search for this relation, however, and lacked statistical power in this respect.

The predominantly non-white Trinidad population has a surprisingly high coronary heart disease mortality. In 1983 for example, the death rate from myocardial infarction in men aged $55-64$ years was reported to be $394 \cdot 3 / 100000$, as compared with $329.5 / 100000$ in the USA. ${ }^{13}$ Preventive measures to reduce the incidence of coronary heart disease in this population are therefore urgently required. As in other communities, high density lipoprotein cholesterol concentration should be included in the assessment of individual risk, using reference values established by the local laboratory. As an approximation, each decrement of $0.025 \mathrm{mmol} /$ litre $(1 \mathrm{mg} / \mathrm{dl})$ in high density lipoprotein cholesterol between the mean and one standard deviation below the mean was associated with a $1.6 \%$ increase in coronary heart disease risk, which was similar to the $2^{\circ}$ increase reported in the USA. ${ }^{3}$

We thank the Government of Trinidad and Tobago, the UK Medical Research Council, and the Pan-American Health Organization for generous support. Nurses L Gajadharsingh, C Cupid and A Gwilliam conducted the fieldwork, and Mrs J Archbald-Doyle and V Hayes supervised the administration of the study.

1 Miller NE, Forde OH, Thelle DS, Mios OD. The Tromso Heart Study. High density lipoprotein and coronary heart disease:

2 Castelli WP, Garrison RJ, Wilson PWF, Abbott RD, Kalousdian S, Kannel WB. Incidence of coronary heart disease and lipoprotein cholesterol levels. The Framingham Study. $\Im A M A$ 1986; 256: 2835-8.

3 Gordon DJ, Probstfield JL, Garrison RJ et al. High density lipoprotein cholesterol and cardiovascular disease. Four prospective American studies. Circulation 1989; 79: 8-15.

4 Miller NE, Miller GJ, eds. Clinical and metabolic aspects of high-density lipoproteins. Amsterdam: Elsevier, 1984.

5 Miller GJ, Beckles GLA, Byam NTA et al. Serum lipoprotein concentrations in relation to ethnic composition and urbanization in men and women of Trinidad, West Indies. Int I Epidemiol 1984; 13: 413-21.

6 Rose GA. The diagnosis of ischaemic chest pain and intermittent claudication in field surveys. Bull WHO 1962; 27: 645-58.

7 Warnick GR, Albers JJ. A comprehensive evaluation of the heparin-manganese precipitation procedure for estimating heparin-manganese precipitation procedure for estimating high-de.

8 Ononogbu IC, Lewis B. Lipoprotein fractionation by a precipitation technique. A simple quantitative procedure. Clim Chim Acta 1976; 71: 397-402.

9 Prineas RJ, Crow RS, Blackburn H. The Minnesota Code. Manual of electrocardiographic findings. Standards and procedures for measurement and classification. Boston: John Wright, 1982.

10 World Health Organization. Manual of the international statistical classification of diseases, injuries and causes of death, 9th revision. Geneva: WHO, 1977.

11 Cox DR. Regression models and lifetables. $f R$ Stat Soc B 1972; 34: 187-220.

12 Watkins LO, Neaton JD, Kuller LH (for the MRFIT Research Group). Racial differences in high-density lipoprotein cholesterol and coronary heart disease incidence in the usual-care group of the Multiple Risk Factor Intervention Trial Am I Cardiol 1 1986; 57: 538-45.

13 World Health Organization Statistics Annual. WHO: Geneva, 1986/87. 